\title{
Embryonic development in the sow on day 17 of gestation. Relationship with the size of the nterus horns
}

\author{
Florence VINCENT, Suzanne WINTENBERGER-TORRES, \\ M. PAQUIGNON, F. du MESNIL du BUISSON \\ Station centrale de Physiologie animale, I. N. R. A., C. N. I. Z., \\ 78350 Jouy en Josas
}

Development of the embryo and of the trophoblastic vesicle was studied in 20 crossbred Large White $x$ Iandrace sows on day $\mathrm{I} 7$ of gestation.

The length of the embryo varied from 2 to $12 \mathrm{~mm}$ (average: $7 \mathrm{~mm}$ ). In one and the same sow the size of the embryos was homogenous (variation coefficient under $20 \mathrm{p}$. 100). There was a close relationship $(r=0.7)$ between the size of the embryo and the number of somites (average: I8 somites).

The trophoblastic vesicles were more a less tight folded. They only overlapped each others exceptionally and occupied the whole uterus. On an average, Io $\mathrm{cm}$ of uterus horn were occupied by $34 \pm 2.4 \mathrm{~cm}$ of trophoblastic vesicle.

The individual length of the trophoblastic vesicles varied much in one and the same horn (for instance $48,59,73,95, \mathrm{I} 47 \mathrm{~cm}$ ). The longer the horn length and the smaller the number of embryos in the horn, the greater the mean length of the vesicles. In horns measuring between roo and $120 \mathrm{~cm}$, this mean length ranged between I 5 and $55 \mathrm{~mm}$ for horns containing 2 and $6 \mathrm{cmbryos}$, respectively; in horns between 140 and $170 \mathrm{~cm}$ long, the mean length of the trophoblastic vesicles were 170 and $102 \mathrm{~cm}$ for 2 and 6 embryos, respectively.

There was no relationship between the length of the trophoblastic vesicle and the size of the embryo.

On day 17 of gestation, the encumbrance of the uterus did not restrict the survival of the embryos. Only further development of the cmbryos might be favoured by uterus horns of greater size. 